\title{
CONSIDERACÕES TEÓRICAS SOBRE O RESGATE DA MITOLOGIA GRECO-ROMANA NO ENSINO FUNDAMENTAL
}

\author{
REDEEMING GRECO-ROMAN MYTHOLOGY IN FUNDAMENTAL TEACHING: \\ DIDACTIC TRANSPOSITIONS
} CONSIDERACIONES TEÓRICAS SOBRE EL RESCATE DE LA MITOLOGÍA
GRECO-ROMANA EN LA ENSEÑANZA FUNDAMENTAL

Bruno Nunes Batista*

(iD) http://orcid.org/oooo-ooo2-3862-1465

Fábio Chang de Almeida**

(iD) http://orcid.org/oooo-0oo1-5053-6186

RESUMO: O artigo busca problematizar o resgate da temática da mitologia greco-romana no Ensino Fundamental. Para isso, o texto foi dividido em três partes: brevemente busca-se analisar a transição entre o pensamento mitológico e a Filosofia Pré-Socrática, discutindo alguns desdobramentos na história do pensamento ocidental. A seguir, discutem-se os motivos da perda de protagonismo da mitologia greco-romana na escola. Por fim, é feita uma proposta de resgate do ensino desse conjunto de saberes, ancorando-se nas ideias de Silvio Gallo e Sandra Mara Corazza.

Palavras-chave: Mitologia grega. Didática. Ensino de História e Filosofia.

Abstract: The article seeks to problematize the rescue of the Greco-Roman mythology in Elementary School. For this, the text was divided into three parts: briefly seeks to analyze the transition between mythological thought and Pre-Socratic Philosophy, discussing some developments in the history of Western thought. Next, the motives for the loss of protagonism of Greco-Roman mythology in the school are discussed. Then, a proposal is made to rescue the teaching of this set of knowledge, anchoring itself in the ideas of Silvio Gallo and Sandra Mara Corazza.

Keywords: Greek mythology. Didactics. Teaching History and Philosophy.

Resumen: El artículo busca problematizar el rescate de la temática de la mitología grecorromana en la Enseñanza Fundamental. Para ello, el texto fue dividido en tres partes: brevemente se busca analizar la transición entre el pensamiento mitológico y la Filosofía Pre-Socrática, discutiendo algunos desdoblamientos en la historia del pensamiento occidental. A continuación, se discuten los motivos de la pérdida de protagonismo de la mitología grecorromana en la escuela. A continuación, se hace una propuesta de rescate de la enseñanza de ese conjunto de saberes, anclando en las ideas de Silvio Gallo y Sandra Mara Corazza.

Palabras clave: Griego mitología. Didáctica. Enseñanza de Historia y Filosofía. 


\section{Palavras de abertura}

No filme Escritores da Liberdade (Freedom Writers, EUA, 2007), uma professora, interpretada pela atriz Hilary Swank, desiste de dar aulas sobre Homero e a Mitologia Grega para adolescentes de uma escola pública. Diante do desinteresse dos alunos pelo tema, ela acaba por substituir aquele conteúdo pela interpretação de um rap do cantor 2Pac. O filme, baseado em uma história real, aborda o contexto de violência, desesperança e desmotivação de um grupo de alunos oriundos de zonas pobres da cidade de Long Beach, Califórnia. A mudança de planos da professora, que substituiu Homero por um cantor de rap, obteve resultados positivos. Os alunos passaram a ter interesse nas aulas e engajaram-se nas atividades propostas nas aulas seguintes. Tomando o filme como uma ilustração, é possível levantar o seguinte questionamento: ainda faz sentido ensinar Homero e Mitologia Grega nas escolas do século XXI?

Como não queremos criar uma expectativa em torno dessa pergunta, já adiantamos a resposta: sim, acreditamos que a Mitologia Grega continua atual e faz sentido para os alunos de hoje. Entretanto, nas últimas décadas nas escolas de Ensino Fundamental e Médio, é inegável que ela perdeu o protagonismo que já teve no passado. Pretendemos neste artigo discutir os motivos desta desvalorização. Em primeiro lugar, através de um enfoque francamente Pós-Estruturalista, discutimos as condições culturais, históricas e subjetivas que possibilitaram a passagem do pensamento mítico à consciência filosófica-científica. Valendo-nos de noções como physis, arqué, logos e cosmo, a ideia é mostrar como interpretações sobre a origem do mundo e o funcionamento da natureza não mais seriam imediatamente provenientes das tradições mitológicas e de narrativas como as de Homero e Hesíodo. Ao contrário: o real entrou na ordem embrionária de um discurso racional, organizado e causal, cujas explicações deveriam advir do próprio mundo e não de formas sobrenaturais, religiosas e misteriosas. Entretanto, a substituição da crença no mythos pela Verdade Laica da Ciência Racional nos trouxe um outro tipo de discurso, mais objetivo, mas cuja certeza Kant, Nietzsche e outros irão problematizar.

Por outro lado, buscaremos compreender porque a mitologia greco-romana perdeu espaço nos currículos escolares do Ensino Fundamental. Sabemos muito bem como somos tributários do Dualismo Platônico arrolado na Alegoria da Caverna, isto é, a divisão entre um mundo inferior e profano, abaixo, e um mundo superior e ideal, acima. Ora, essa linha dividida vem nos levando a, frequentemente, almejar as conquistas mais grandiloquentes possíveis através da escola, como se ela pudesse resolver, por si só,

\footnotetext{
* Doutor e mestre em Geografia pela Universidade Federal do Rio Grande do Sul (UFRGS). Professor na Universidade Federal de Pelotas, Instituto de Ciências Humanas.

E-mail: brunonunes.86@hotmail.com

** Doutor em História pela Universidade Federal do Rio Grande do Sul (UFRGS). Graduado em História e Geografia. Professor na Prefeitura Municipal de Porto Alegre (PMPA).

Contato: history.chang@gmail.com
} 
os problemas do mundo, engendrando cidadania, democracia, criticidade e assim por diante. Como isso tudo não se concretiza, produz uma entre outras tantas frustrações do trabalho docente.

Justamente por isso, estaremos nos alicerçando num projeto de Educação Menor. Corolário de uma junção da Filosofia da Diferença de Gilles Deleuze com a Pedagogia de Silvio Gallo, trata-se de uma possibilidade que não almeja produzir um mundo perfeito através do ensino de Filosofia e História, mas sim dar uma outra apresentação aos conteúdos escolares por meio de um trabalho de criação do professor, cuja amplitude é limitada por cada arranjo local, cultural e histórico. Com efeito, estamos falando de uma intenção que busca enaltecer o papel autoral na docência. É por isso que, na esteira desse processo, também nos utilizaremos das operações presentes na Didática da Tradução, onde o pensamento de Sandra Mara Corazza e outros nos será de grande valia.

\section{A mitologia em segundo plano: a ruptura pré-socrática}

Para que possamos compreender em que estágio a importância dos mitos desceu a um segundo plano interpretativo, vale que façamos um retorno ao processo de ruptura entre mitologia e a consciência filosófica. Nesse sentido, cabe diferenciar uma da outra.

Em primeiro lugar, vale lembrar que o pensamento mítico é característico das sociedades antigas, mas não exclusivamente destas. Ele reúne experiências e narrativas variadas até compor um mito geral. O mito relaciona e faz elementos heterogêneos agirem uns sobre os outros. Com essas fontes heterogêneas confecciona a explicação sobre a origem, forma ou funções das coisas e da natureza. O mito representa uma verdade intuída, não precisando de provas para ser aceita pelo grupo. O mito não tem nenhuma obrigação de encontrar correspondência na realidade. Conforme Ernst Cassirer:

$O$ verdadeiro substrato do mito não é de pensamento, mas de sentimento. $\mathrm{O}$ mito e a religião primitiva não são, de maneira alguma, totalmente incoerentes, nem destituídos de senso ou razão; mas sua coerência depende muito mais da unidade de sentimento que de regras lógica. (CASSIRER, 1977, p. 134).

A característica mais evidente presente na mitologia advém do seu caráter de narrativa, que é transmitido de uma geração à outra por intermédio dos mais experientes. Essa narrativa, entretanto, não flui de uma verdade absoluta 
e/ou científica, mas de uma construção sobrenatural que origina, como ponto de partida, os eventos e as existências posteriores. Normalmente coletivo, o pensamento mítico não faz uso de princípios abstratos. Trata-se de um processo de ordenação de elementos concretos para significar a realidade, embora não busque com isso a verdade objetiva. O pensamento mítico pertence ao campo do pensamento e da linguagem simbólica. Malgrado coexistam, o pensamento e a linguagem simbólica são frequentemente contrários ao pensamento e linguagem conceituais. Contudo, Veyne (1983, p. 14) nos lembra que nem sempre o pensamento mítico e o logos se opõem como o erro e a verdade, tendo sido o mito na Grécia Antiga tema para reflexões profundas.

Com efeito, ao tentarem entender questões complexas como a vida, a morte e a natureza, os gregos buscavam suas explicações em supostas ações de deuses e seres divinos. Todavia, não tentavam entender as ações dos deuses de uma forma minuciosa. Acreditava-se que determinados processos aconteciam, por exemplo, devido a brigas entre os deuses (VEYNE, 1983). Com efeito, na antiguidade estava-se lidando com uma explicação alegórica, cuja correia transmissora dava-se por meio da tradição oral ou, do mesmo modo, por poemas, que eram narrados por artistas que recitavam suas próprias composições (os aedos), ou replicavam poemas escritos por outros autores (os rapsodos) (MARCONDES, 1997). A narrativa mítica organizava as relações sociais legitimando a permanência de um sistema de proibições e permissões. Ela era a negação do presente e podia tanto possuir uma função compensatória como regularizadora. A mitologia atribuía sentido analógico e metafórico às coisas, aos fatos, às instituições, aos seres humanos ou seres naturais. O símbolo mítico encarnava aquilo que simbolizava, ou seja, o símbolo era a própria coisa simbolizada, ao invés de representada.

Bem, é com notável diferenciação que a origem da Filosofia se desenrolaria. Sobre isso, muito já foi escrito e não nos compete retomar linha por linha essa historicidade. Preferimos, resumidamente, dizer que foi entre os séculos VII e VI a.C. que, gradualmente, a mitologia perde parte da sua influência enquanto cosmovisão de sociedade. Sob os efeitos de mudanças sociopolíticas e econômicas como as viagens marítimas, o surgimento da vida urbana e as invenções da moeda e da escrita alfabética, emergiria a consolidação de um novo espaço público, no qual a política seria intensificada e o discurso, por sua vez, substituiria o mito (MARCONDES, 1997). De fato, é na pólis, e através da pólis, que cada cidade-Estado deveria decidir, racionalmente, suas atividades futuras.

Os primeiros filósofos foram inovadores em dois aspectos fundamentais: em primeiro lugar, tentaram com- 
preender o mundo sem o recurso ao pensamento mítico, à revelação, à autoridade ou à tradição. Ao mesmo tempo, eles se preocupavam em ensinar outras pessoas a usarem a razão e pensarem de maneira autônoma. Dessa forma, foram os primeiros mestres a não transmitirem um corpo de conhecimento puro e intacto, mas encorajar seus discípulos a discutir, argumentar e propor suas ideias. A união desses dois paradigmas forma a base do que atualmente chamamos de pensamento racional. Uma vez introduzida, essa nova maneira de pensar levou a um avanço no conhecimento e entendimento humanos sem precedentes na história (MAGEE, 1999, p. 12).

Ora, sob a égide dessa nova perspectiva, podemos acompanhar o surgimento gradativo de uma narrativa centrada na racionalidade, colocando em segundo plano as origens míticas e sacralizantes. Desse modo, algumas noções fundamentais foram transformadas, configurando uma nova leitura de mundo. Dentre elas, ressaltamos cinco posicionamentos: a physis, a causalidade, a arqué, o cosmo e o lógos (CHAUÍ, 2002).

Inicialmente, a physis. Se fôssemos lembrar dos mitos de origens ou das interpretações sobre a natureza, veríamos que elas eram explicadas por meio de ações circunstanciais ou intempestivas das divindades. Esse panorama é alterado: agora, a força-originária, motor primeiro que canaliza as ações naturais, responde por uma junção entre a essência e a existência, feita pelo mundo natural. Aliás, essas relações se dariam através de uma causalidade, explicando um efeito por aquilo que o antecede e determina; logo, seria necessária uma investigação dos nexos causais que, levando uma coisa à outra, chegaria ao primeiro princípio que explicaria o ponto inicial da natureza: trata-se da arqué. Na Filosofia pré-socrática, ela significaria uma tentativa de compreender o caráter geral, e inicial, que permearia a realidade na sua totalidade. Encontrando-a, conseguiríamos entender o mundo como um cosmo, isto é, uma materialidade ordenada na qual as causas e os efeitos se dão de modo sistemático a partir de determinadas leis gerais: cosmo, por conseguinte, difere-se de caos. Por último, é no acesso à realidade através de seguros princípios que o lógos é alcançado, constituindo uma palavra balizada pela razão e que se explica utilizando instrumentos empíricos e lógicos.

Com o desenvolvimento dessas cinco noções, encontramos enfim a emergência de uma atitude filosófica que tem no seu caráter crítico a correia para suplantar o pensamento mitológico. É dessa base constitutiva que a Filosofia se desenvolveria nos próximos séculos, sempre orbitando em torno de uma ou de outra dessas noções fundamentais. Pouco a pouco, a sacralidade dos mitos se esvaneceria em posição secundária na grade de inteligibilidade ocidental. 
Cada um à sua maneira, os filósofos enquadrados na chamada corrente pré-socrática balizavam suas reflexões tomando como âncoras a criticidade filosófica. Lembremos, como ilustração, dos jônios, dos pitagóricos, dos eleatas e dos atomistas. Tales de Mileto, por exemplo alicerçava sua arqué na água, por meio da qual seriam obtidas todas as substâncias presentes na Terra - "tudo é água, tudo vem do úmido". Anaxímenes, enquanto isso, discordava de Tales remetendo a origem da matéria ao ar. Essa seria uma discussão em cuja esteira Heráclito depositaria suas reflexões. Para o filósofo de Éfeso, a substância primordial seria o fogo, um elemento volátil da natureza que representaria a própria vida: uma chama que se acende e que se apaga. Não por acaso, o pilar fundamental da filosofia heraclitiana se ancorava na "luta dos contrários", que pressupunha uma constante transformação e fluência da realidade, afinal "não se pode entrar duas vezes no mesmo rio" (HERÁCLITO, 1999, p. 97).

Não nos cabe, aqui, dar conta por completo desses desdobramentos. Vamos limitar-nos a afirmar que, por milênios, temas como a arqué, o cosmo e a physis não encontrariam ponto pacífico de discussão. Pitágoras defendia a tese de que tudo era feito de números - e teve seus seguidores. Parmênides dividia o conhecimento entre a verdade (alétheia) e a opinião (doxa), estabelecendo que a primeira é única, imutável e eterna. Empédocles propôs a teoria dos quatro elementos (água, terra, fogo e ar), enquanto Leucipo e Demócrito inauguravam nas suas escolas o atomismo, isto é, a ideia segundo a qual tudo proveria de partículas originárias indivisíveis e invisíveis. (PESSANHA, 1999). Ora, nenhum deles ofereceu-nos as chaves decodificadoras para entender, verdadeiramente, de onde viemos e para onde estaríamos indo. Tampouco esses primeiros filósofos concordavam completamente em termos de método, razão e natureza. Todavia, num ponto a convergência esteve evidente: a mitologia não dava mais conta de explicar, efetivamente, a matéria-prima do universo e as suas operações em termos regulares e previsíveis (MARCONDES, 1997)

A história da Filosofia não termina por aqui. Por outro lado, também não temos a intenção de atribuir maior valor seja ao pensamento mitológico, seja ao conhecimento filosófico-científico. O que queremos pôr em relevo, na verdade, é que das entranhas dessa ruptura emergiu uma vontade de verdade que, a rigor, nos traria um desejo por certezas absolutas e um certo menosprezo, enquanto isso, por saberes que não fossem imediatamente aplicáveis ou que, tal como nos mitos gregos, estivessem mais próximos das emoções, das fantasias, dos imaginários e das imprevisibilidades. Talvez o mais sólido exemplo dessa perspectiva esteve presente na filosofia socrática-platônica, cuja eclosão se deu em torno da cidade-Estado de Atenas. 
A história da Grécia do século V a.C. passou por uma série de transformações que alteraram profundamente a organização interna das suas cidades. O caso de Atenas, no entanto, é bem particular. Tratava-se de uma cidade influenciada tanto pelos fluxos migratórios que periodicamente recebia quanto por sua localização geográfica, que proporcionava uma predisposição maior para o comércio. Porém, após a vitória dos gregos perante os persas, nas chamadas Guerras Médicas, Atenas se colocou no lugar de centro cultural do mundo antigo, em que conviviam pensadores, comerciantes e artesãos de diferentes personalidades. É verdade que ela se assemelhava em estrutura social à estratificação de Esparta, no que se referia ao uso e apropriação das terras, visto que os detentores de espaços privilegiados estavam nas posições mais fortes de poder. No entanto, viria a existir um cenário um pouco mais equilibrado no que tocava à propriedade privada, sendo ele resultado da passagem de uma oligarquia à democracia (ANDRADE, 2002). Essa ruptura se desenrolava na esteira, inclusive, de reformas contundentes como as de Sólon e Clístenes: procurando atender aos desejos de uma classe emergente que enriquecia na sociedade ateniense, esses governantes elaboraram propostas visando instigar uma participação igualitária e isonômica dos membros considerados cidadãos. Em outras palavras, a intenção seria incluí-los ativamente e democraticamente no espaço da pólis.

Tratava-se de uma democracia reservada a uma parcela pequena da sociedade ateniense. No entanto, é importante entender que nesse espaço privilegiado, os cidadãos podiam exercer plenamente seu direito à fala e ao debate. Logo, o princípio político não se baseava na representatividade: os sujeitos deveriam preocupar-se com a retórica, pois não haveria um porta-voz dos seus interesses. É por tal conjuntura que em Atenas ${ }^{1}$, o jovem proveniente das famílias abastadas seria iniciado em diversas disciplinas por educadores experientes, para que tanto pudesse tornar-se um bom governante, quanto, também, desenvolvesse habilidades no trato com a oratória, a retórica, a argumentação e a fala em público (GAUTHIER, 2010).

É nesse quadro que se destacava uma figura como a de Sócrates. Carismático, atento e reflexivo, tratava-se de um filósofo que se via como um "parteiro de ideias". Através de um método muito particular - a maiêutica -, seu objetivo era oferecer aos seus ouvintes uma condução mais segura aos caminhos da verdade, demonstrando as contradições internas do pensamento de cada sujeito e auxiliando-os na descoberta da vida racional. É fato que Sócrates, pelo menos nos primeiros diálogos platônicos, aparece como um homem humilde e que assume, de antemão, que não é dono de um conhecimento verdadeiro. Mas também é um
1 Caso bem diferente de Esparta: sociedade militarizada, de estamentos, sem mobilidade social, e tendo como instituição de comando uma oligarquia privilegiada, é a força dessa própria estruturação que desembocava num modelo muito particular de educação. Essa começava, em média, aos 7 anos, e ia até os 30 anos, quando a criança oriunda dos esparciatas era retirada da família para passar por um intenso treinamento militar, de forma que entendesse que servia à Esparta, e não à família. Nesse percurso, uma vez vitorioso, aos 30 anos o indivíduo receberia o título de soldado-cidadão, ganhando na sequência os benefícios que isso agregava (FINLEY, 1991). Destacamos que pelos resultados desse tipo de educação para o militarismo, haveria consequentemente uma menor preocupação com a oratória e o discurso - vide a origem do termo "lacônico", que se referia aos espartanos da Lacônia, unidade regional da Grécia na qual se treinavam os soldados para o silêncio (FINLEY, 1991). 
fato que ele, de algum modo, aponta em diversas passagens registradas por seus seguidores que a verdade existiria, cabendo a Filosofia busca-la. Só por essa característica já poderíamos localizar na atitude socrática uma semelhança aos primeiros filósofos "pós-pensamento mitológico", afinal as próprias noções fundamentais da Filosofia incluíam um desejo de descobrir a primeira e a última razão de tudo.

Todavia, é nos escritos considerados maduros de Platão que um conhecimento filosófico realmente dualista ganha corpo. Seja pela metáfora da "escada" do conhecimento ( $\mathrm{n}^{\prime} O$ Banquete), seja pela divisão entre um mundo cavernoso e um mundo iluminado presente no Livro Sétimo d'A República, ou, de forma semelhante, pela Teoria das Formas presente em vários dos seus diálogos, o que encontramos é um esforço monumental por apreender um conhecimento seguro, perfeito, certo, correto e - por que não? - belo. E a própria história posterior da Filosofia, na maior parte das vezes, encarregou-se de levar a bom termo essa disposição. Aristóteles, Bacon, Descartes... Todos eles se debruçaram sobre o projeto platônico e, cada um a seu modo, dividiram o mundo entre existência e essência, objeto e sujeito, aparência e conhecimento, dedução e indução, razão e emoção.

Essa crença nos princípios racionais e no alcance de um saber último e perfeito não foi unanimidade. Era o caso do relativismo humanista dos sofistas, que rejeitavam a possibilidade de um conhecimento em instância absoluta. Também os céticos helenistas, liderados por Pirro de Élis, assumiam grandes desconfiança sobre o alcance da certeza: a crença na verdade é uma ingenuidade tremenda, que só nos prejudica no entendimento da vida.

Como sabemos, a Modernidade de alçar essa vigilância crítica ao saber racional às últimas escalas. Kant expõe na "Crítica da razão pura", como ilustração, o seu criticismo, segundo o qual tudo o que experienciamos - percepções, sensações, lembranças, pensamentos - é apreendido por nós através de nosso aparelho corporal e assume as formas que assume por causa da natureza desse aparelho. Tudo aquilo capaz de ser apreendido por este aparelho corporal, regido pelos cinco sentidos, pode ser experienciado pelo ser humano. Entretanto, é lógico acreditar que o mundo real vai além da capacidade humana de percepção, e aquilo que não pode ser apreendido não pode se tornar uma experiência. De acordo com Kant, aquilo que as coisas realmente são - independentemente de nossos modos de percepção e pensamento - é algo de que não podemos formar nenhuma noção (MAGEE, 1999, p. 132-133). Portanto, a verdade pode estar além do nosso alcance.

Para Kant, existem dois limites para o conhecimento humano. O primeiro é o conjunto de tudo que existe, a 
realidade total, independente da nossa capacidade de experiência. O segundo limite é um subconjunto do primeiro, correspondente à fração da realidade que somos capazes de experimentar. Certamente o segundo limite é mais restrito que o primeiro. Em outras palavras, a soma total do que podemos apreender é igual à soma total de tudo aquilo que as nossas faculdades humanas são capazes de captar. Onde nosso conhecimento não alcança, existem coisas além de nossa apreensão. E o fato de estarem além de nosso conhecimento não significa que tais coisas não existam (MAGEE, 1999, p. 133-134).

Kant admitia inspiração no pensamento de John Locke, segundo o qual nossos sentidos constituem a única interface direta entre nós e a realidade externa. Somente por meio dos sentidos podemos ficar conscientes das coisas vindas de fora. Conforme Locke, se começarmos a realizar operações mentais a partir de dados não provenientes de nosso aparelho sensorial, teremos prescindido da única ligação de nossa mente com a realidade externa. Nesse caso, aquilo que a mente produzir estará desconectado do mundo externo. Para Locke, nosso entendimento da realidade deve sempre derivar do que foi experimentado por meio dos sentidos (MAGEE, 1999, p. 102-105).

No entanto foi Nietzsche, no crepúsculo do século XIX, que desferiu as mais incisivas críticas até então feitas à vontade de verdade. Esse é um traço marcante ao longo de toda a sua obra. Mas é no escrito Verdade e mentira no sentido extra moral, de 1873 , que esse singular pensador nos deixou as palavras mais famosas sobre um conhecimento verdadeiro: segundo ele, a verdade seria uma mera ficção de linguagem, feita de convicções que, de tanto repetidas, passaram a ser tidas como sagradas e naturais. Nietzsche rejeita esse quadro, chegando a afirmar que as verdades nada mais seriam do que "ilusões das quais se esqueceu que são, metáforas gastas que perderam a sua força sensível, moeda que perdeu sua efígie e que não é considerada mais como tal, mas apenas como metal" (2001, p. 12-13).

Na esteira do ceticismo, muitas e importantes reflexões foram e vêm sendo produzidas. Entretanto, é preciso admitir que a subjetividade e a incerteza, de fato, perderam o combate para uma Filosofia mais técnica, objetiva e mecanicista. Com as emoções, a poesia, as artes e a criatividade perdendo terreno para o tecnicismo burocrático e produtivista das diversas fases do modo de produção capitalista, o próprio conhecimento passou a ser avaliado pelos elementos imediatamente aplicáveis que ele possuiria. No bojo do pragmatismo, vale aquilo que é útil - e mesmo o ensino das Ciências Humanas não escapa a tais teias de poder e saber. A perda de protagonismo dos relatos míticos está associada 
ao fato de que eles nunca tentaram - e nem deveriam - oferecer garantias de verdade e critérios de certeza sobre a vida. Com efeito, a imprevisibilidade dos Deuses e a instabilidade das suas decisões sempre assumiram, de algum modo, que a complexidade da existência humana possui uma brecha inapreensível à razão, à ciência e à técnica.

\section{A mitologia greco-romana na escola}

Durante décadas o Brasil praticou uma educação de forte influência positivista, centrada cultural, histórica e geograficamente na Europa e que valorizava os "grandes personagens" da história oficial. A partir dos anos 1990, houve um movimento de revalorização da cultura brasileira nas escolas. Passou-se a incentivar o ensino dos mitos e ritos indígenas e também das mitologias de origem africana. Essa mudança de olhar foi necessária e muito bem-vinda, ajudando a corrigir distorções pedagógicas que moldavam uma educação eurocentrista. Contudo, mesmo que de maneira indireta, esse processo foi um dos motivos que levou à desvalorização do ensino da mitologia greco-romana nas escolas, pois ela supostamente estaria vinculada àquele antigo e ultrapassado modelo educacional.

Tratava-se de uma epistemologia que valorizava um sistema de ideias fechado que promovia práticas e discursos favoráveis a um grupo social específico, dominante na história do ocidente: o branco europeu e norte americano. Desde a formação colonial do Brasil, esta tendência epistemológica (mesmo que às vezes apenas sutilmente percebida) delineou uma educação em favor do "branco" em relação aos padrões de beleza, história, origens culturais, produções orais e escritas, etc. Um exemplo foi justamente, durante muito tempo, a exclusão das mitologias indígenas e africanas e a presença predominante da mitologia greco-romana nos currículos escolares (SANTOS, 2006, p. 74).

Por outro lado, uma "Filosofia da Verdade" não poderia prescindir de uma "Pedagogia da Verdade". De certa forma, as raízes da Pedagogia Moderna se encontram na junção entre essas duas intencionalidades. Parte do ensino da mitologia se perdeu nesse caminho.

Para entendermos os deslocamentos desse processo, um profícuo começo de conversa é lembrarmos da Didática Magna de Comenius (2006). Nesse verdadeiro tratado, temos acesso a um conjunto de prescrições endereçado ao público docente. Envolto por um cenário do aumento de alunos na escola e em meio às explosões demográficas no ocidente europeu, o líder religioso Comenius não se furta da complexa tarefa de conduzir os professores a um estágio ideal de ensino e aprendizagem, orientando-os detalhadamente sobre as maneiras corretas de se empreender um 
trabalho pedagógico. Pelo rigor das suas proposições e a extensão das suas receitas didáticas, muitos especialistas consideram, com certa dose de razão, a Didática Magna como obra fundadora da Pedagogia Moderna, surtindo seus efeitos até a contemporaneidade. Não iremos retomar linha por linha o pensamento comeniano. Vamos, porém, destacar duas consequências ainda presentes na formação docente.

Em primeiro lugar, cremos que um dos legados deixado por essa obra foi constituir a base do que Veiga-Neto (2012) conceituou como as pragas pedagógicas. Na visão desse pesquisador, características comuns nas licenciaturas, sejam elas o excesso de metodologias e receituários didáticos, assim como os messianismos delirantes que desejam reformar o mundo através da educação, foram fortalecidos na esteira da proposta de Comenius. Como resultado, não apenas somos cobrados como também tendemos a esperar da educação e dos nossos componentes curriculares aquilo que eles, talvez, não possam nos oferecer. Se lembrarmos que entre as exigências de uma suposta educação contemporânea estariam a formar sujeitos não apenas em termos de conhecimentos, mas também no que tange à cidadania, ao mercado de trabalho, ao espírito científico, à cultura pluralista e aos direitos humanos, é possível quem sabe perceber como as teleologias pedagógicas têm um grande potencial para nos frustrar.

A segunda consequência também nos preocupa. É compreensível a força que Comenius despendeu em descrever passo a passo os processos de ensino e aprendizagem; basta lembrarmos que quando a escola se massifica, não haviam professores formados em número suficiente: leigos, de fato, passaram a lecionar nas escolas, e algum alicerce se fez efetivamente necessário. No entanto, como nos explica Alves (2005), essa precária perspectiva inicial também acabou se desdobrando, por tabela, numa perda da autoria do professor nas décadas seguintes: tendo antes um papel de construtor rigoroso dos seus materiais didáticos (vertidos a um compêndio), gradativamente ele foi tornando-se mero receptáculo de livros e receituários pedagógicos, que não só se baseavam nas pragas pedagógicas enumeradas por Veiga-Neto como, principalmente, estabeleciam minuciosamente o que o docente deveria fazer em sala de aula. Quando pensamos na enxurrada de materiais de apoio, planos de aula, formações pedagógicas e palestras dirigidas aos professores atualmente, não há como não remeter esse quadro às bases construídas na Didática Magna.

É óbvio que essas duas perspectivas não se coadunam a uma proposta que deseja transpor didaticamente a mitologia para o Ensino Fundamental. Por dois motivos. 
Inicialmente, porque a imprevisibilidade e aventura presentes nas ações sobrenaturais das divindades já não se encaixariam, de antemão, a um presente educacional em que termos como eficiência, eficácia, produtividade, cientificidade e empreendedorismo rondam - às vezes mais do que deveriam - os currículos da Escola Básica. De forma semelhante, são as próprias características acidentais, circunstanciais e subjetivas encontradas nas narrativas mitológicas que inviabilizam um planejamento docente ancorado em planos de aula construídos a priori por alguém de fora do contexto escolar. Com efeito, é assumindo um papel de criação artesanal, procurando fazer da sua aula uma obra de arte tal como as poesias homéricas, que o professor das humanidades conseguiria marcar terreno num panorama que só poderia ser autoral.

Assim, com o objetivo de atribuir um pouco mais de significado aos conteúdos sobre a mitologia greco-romana nas aulas de História e Filosofia, nossa intenção não é desmerecer as outras mitologias, mas ao contrário, mostrar que elas podem compartilhar na escola uma função didática importante. Queremos dar maior abertura aos relatos míticos, mostrando não apenas como eles são significativos, mas também afirmando que eles estão, por debaixo das aparências, presentes como nunca no imaginário e na realidade, nos corações e nas mentes, dos milhões de jovens matriculados nas séries finais do Ensino Fundamental brasileiro. Mas essa atitude, no entanto, nos exigiria uma outra atitude pedagógica, certamente não aquela redentora, finalista, messiânica e ritualizada da Modernidade e que, de um certo modo, ressoava nas narrativos da tradição mítica ocidental greco-romana. Em outros termos, precisaríamos de uma pedagogia menor, que nos permitiria falar em nome próprio.

No bojo dessa perspectiva que estamos assumindo, um pensamento como o de Sílvio Gallo nos é de indiscutível valia. Seguindo um fio filosófico preconizado por Gilles Deleuze e Félix Guattari, esse autor propõe o que chama de Educação Menor (GALLO, 2016). Como no nome da mesma já nos possibilita inferir, trata-se de um ponto de vista que rejeita o papel do professor como executor de manuais didáticos. Por isso mesmo, suspeita das características disseminadas por um pensamento pedagógico hegemônico, que divide moradia com os parâmetros e as diretrizes da Educação Nacional que só serviriam à manutenção do status quo. Desse lugar-comum são disparadas as ordens que estão "sempre a nos dizer o que ensinar, como ensinar, para quem ensinar, por que ensinar" (GALLO, 2016, p. 65). É esse o lugar onde a Educação Menor não quer estar e que combate cotidianamente. Sem a pretensão de alcançar a totalidade, encontramos nessa proposta um tour de force 
que libera o pensamento docente de um sono pedagógico e lhe permite a constituição de uma singularidade criativa, a fim de empreender aulas que desequilibrem não só os alunos, como também o professor em si mesmo.

Nessa conjuntura que não se fecha, mas está sempre em aberto e no devir, o trabalho docente não segue modelos nem, tampouco, impõe soluções. Sabe conscientemente que tratados pedagógicos de "como ensinar e aprender" ficam do lado de fora da sala de aula, e só são bem-vindos quando utilizados à guisa de desconstrução, ou através de uma recontextualização do professor, que empreende uma didática a partir das condições objetivas e subjetivas proveniente do seu espaço geográfico. Em outro viés, o professor que pratica a Educação Menor igualmente que o currículo que lhe é imposto para executar, como se fosse ele um "apertador de botões" de uma fábrica fordista, não é sagrado e nem biblicamente intocável, mas um pergaminho maleável e híbrido, cheio de frestas e linhas de fuga (DELEUZE, 1990) que permitem a introjeção de elementos novos e vivos. Por outro lado, esse docente também sabe que as matrizes de referências e as bases curriculares de boas samaritanas nada têm, sendo infiltradas por relações de poder e saber de ponta a ponta; logo, ele põe sob vigilância essas diretrizes, até mesmo indo de encontro a elas em diversos momentos.

Num caminho que se desenrola na mesma postura de Gallo (2016), poderíamos nos valer do pensamento de Corazza $(2008,2013)$. Tocando um projeto nos últimos anos que têm como base defender o professor como um artista da aula, tal autora construiu uma sólida matriz conceitual que podemos resumir como a Didática da Tradução. Segundo Corazza (2008, 2013), a aula, enquanto transposição de um currículo, abarca uma faixa tradutória, e nessa estariam incluídas tanto as aulas pretensamente boas quanto as supostamente ruins. Portanto, todo professor elabora sua marca tradutória, que faz do currículo construído uma peça transformada, transfigurada, imbuída das impressões que ele elaborou. É verdade que o professor não pode virar as costas para os currículos oficiais; todavia, eles tanto não podem ser fielmente replicados, assim como cada docente impõe uma marca e um olhar pessoal sobre esses arquivos. Por consequência, o professor-tradutor não deve estar em posição de dívida com o currículo "original". Visto que a tradução do currículo não é uma imagem e tampouco uma cópia, no processo tradutório ela atravessa uma transformação. É por isso que a tradução do conhecimento, quando não tem a pretensão de copiá-lo, atribui vitalidade ao currículo original, pode completá-lo e mesmo engrandecê-lo ainda que provisoriamente, pois as aulas são, também, temporárias. 
Conforme sugere Corazza (2013), o processo didático-tradutório pode operar-se através de alguns estádios metodológicos: a) o nível curricular, edificado a partir da deliberação do professor acerca de quais temáticas são significativas; b) a irreverência temática, isto é, a possibilidade de caos e criatividade que poderia problematizar o pensamento; c) o manejo da linguagem educacional, tocando a multiplicidade de instrumentos da língua, sendo o teatro, a poesia, a música e os intertextos vistos como formas de variar o estado da arte pedagógico; e d) o ajuste, isto é, o planejamento artesanal que elabora detalhes, sequências e momentos de desequilíbrio que energizam a aula.

Com uma base na Educação Menor e outra na Didática da Tradução, pensamos ter disponível um motor de construção para tornar o ensino da mitologia mais significativo e diferente. Sem a busca da verdade positivista, e evitando os campos minados da Redenção Iluminista e sua Modernidade Pedagógica, não nos interessa considerar nossa didática como a mais correta; não temos o direito de prescrever aos professores como dar as suas aulas sobre a mitologia greco-romana. $\mathrm{O}$ que procuramos colocar em relevo foi uma via menos redentorista e menos colonialista para o ensino da mitologia greco-romana.

\section{Considerações finais}

Com o percurso do artigo, enfim, concluído, resta-nos panoramicamente indicar algumas conclusões provisórias que consideramos mais marcantes. À frente do enfoque, deixamos em relevo a seletividade dos componentes curriculares nas humanidades, dentre elas a História e a Filosofia, que enaltecem algumas linhas de trabalho enquanto suplantam outras. Nesse sentido, como vimos, o caso do ensino da mitologia é exemplar. Detentor de uma primazia durante milhares de anos na civilização ocidental, trata-se de uma narrativa que, com o desenvolvimento da consciência filosófica, foi perdendo terreno para os sistemas racionais e os mecanicismos de causa e efeito que, gradualmente, passaram a referendar o que conhecemos por pensamento científico. Sabemos da relevância fundamental desse na história da humanidade; discordamos, no entanto, do papel subalterno desde então reservado àquele.

É por tal motivo que quisemos ilustrar como a noção de verdade é uma construção que tem data marcada na história da Filosofia. Cientes disso, talvez possamos entender como o que hoje tomamos tomar como certo e natural talvez seja mais incerto e artificial do que imaginávamos ser.

Dentre esses elementos de suspeita, podemos tranquilamente incluir a Pedagogia e o posterior processo de formação de professores. Tributária da fórmula comeniana, que 
supunha uma organização do trabalho didático submissa a rotinas previstas a priori por especialistas e manuais de apoio, ainda somos reféns de uma condição subalterna, cujo principal desejo é expelir do seu seio conteúdos e expressões que expressem diferença e criatividade. No entanto, uma vez munidos de uma abordagem Pós-Estruturalista, que rejeita a noção de totalidade e trabalha por efeitos singulares, talvez possamos trabalhar e pensar nossa docência de uma outra maneira, procurando restabelecer uma autoria que nos foi barrada, mas que permanece sendo nosso maior patrimônio.

\section{Referências}

ALVES, Gilberto Luiz. O trabalho didático na escola moderna: formas históricas. Campinas: Autores Associados, 2005.

ANDRADE, Marta de. A vida comum: espaço, cotidiano e cidade na Atenas Clássica. Rio de Janeiro: DP \& A, 2002.

CASSIRER, Ernst. Antropologia filosófica. São Paulo: Mestre Jou, 1977.

CHAUI, Marilena. Dos pré-socráticos a Aristóteles. São Paulo: Companhia das Letras, 2002.

COMENIUS, Jan. Didática magna. São Paulo: Martins Fontes, 2006.

CORAZZA, Sandra Mara. Os cantos de Fouror: escrileitura em filosofia-educação. Porto Alegre: Sulina, Editora da UFRGS, 2008.

CORAZZA, Sandra Mara. Didática-artista da tradução: transcriações. Mutatis Mutandis: Revista Latinoamericana de Traducción, v. 6, n. 1, 2013.

DELEUZE, Gilles. Que és un dispositivo? In: BALIBAR, Etinenne; DREYFUS, Hubert (Orgs). Michel Foucault, filósofo. Barcelona: Gedisa, 1990.

FINLEY, Moses. Economia e sociedade na Grécia Antiga. São Paulo: Martins Fontes, 1991.

GALLO, Sílvio. Deleuze \& a Educação. Belo Horizonte: Autêntica, 2016.

GAUTHIER, Clemont. A evolução das ideias e das práticas pedagógicas da Antiguidade até o século XX. In: GAUTHIER, Clemont; TARDIF, Maurice.(Orgs.).Apedagogia: 
teorias e práticas da Antiguidade aos nossos dias. Petropólis, RJ: Vozes, 2010.

HERÁCLITO DE ÉFESO. Sobre a natureza. In: PESSANHA, José Américo Motta (Org.). Os pré-socráticos: fragmentos, doxagrafia e comentários (Coleção Os Pensadores). São Paulo: Nova Cultural, 1999.

MAGEE, Bryan. História da filosofia. São Paulo: Loyola, 1999.

MARCONDES, Danilo. Iniciação à História da Filosofia: dos pré-socráticos a Wittgenstein. Jorge Zahar, 1997.

NIETZSCHE, Friedrich. Verdade e mentira no sentido extra moral. Comum, v. 6, n. 17, jul.dez. 2001.

PESSANHA, José Américo Motta (Org.). Os pré-socráticos: fragmentos, doxagrafia e comentários (Coleção Os Pensadores). São Paulo: Nova Cultural, 1999.

SANTOS, Ana Katia Alves dos. Infância Afrodescendente: epistemologia crítica no Ensino Fundamental. Salvador: UFBA, 2006. Disponível em: <https://repositorio. ufba.br/ri/handle/ufba/212>. Acesso em 15 mai. 2020.

VEIGA-NETO, Alfredo. É preciso ir aos porões. Revista Brasileira de Educação, v. 17, n. 50, mai.-ago. 2012.

VEYNE, Paul. Acreditaram os gregos nos seus mitos? Lisboa: Edições 70, 1983.

Enviado em: 28-02-2019

Aceito em: 07-07-2020

Publicado em: 05-08-2020 